\title{
Impact of diseases on aquaculture in the Asia-Pacific region as exemplified by epizootic ulcerative syndrome (EUS)
}

\begin{abstract}
Traditional production systems rely on extensive management regimes that involve low stocking densities and input levels. In recent years, however, the aquaculture industry has evolved into a major force in the regional aquatic economy. As a consequence, a major structural change has occurred, leading to capital intensive production systems with high stocking densities and high operating costs. While this structural change has enabled many Asian countries to increase their aquaculture production multifold, it has not been without environmental and socio-economic impacts; among the most important are increasing fish health issues. Fish diseases are the major risk factor in commercial aquaculture, with millions of dollars lost annually. There is a tendency for epizootic outbreaks to spread to other areas; lack of knowledge on the aetiology and spread of these fish diseases requires much research. A case in point is epizootic ulcerative syndrome (EUS). Despite regional collaborative research efforts from Australia to India over the last 6 years, scientists have still not been able to establish the primary factor behind this disease. As this example shows, the lack of knowledge in fish health remains a major constraint in the development of the regional aquaculture industry. This paper identifies long-term measures that producing countries must implement to ensure the sustainability of the industry. These include quarantine systems to prevent the spread of exotic pathogens, together with diagnostic services. There is also an urgent need to improve husbandry techniques to reduce fish stress, and to train operating personnel adequately.
\end{abstract}

Keyword: Aquaculture; Fish diseases; Epizootic ulcerative syndrome (EUS); Fish health 